\title{
Phenylmethanesulfonyl fluoride elicits and intensifies the clinical expression of neuropathic insults*
}

\author{
A. Moretto, M. Bertolazzi, E. Capodicasa, M. Peraica**, R. J. Richardson****, M. L. Scapellato and M. Lotti \\ Universita' degli Studi di Padova, Istituto di Medicina del Lavoro, via J. Facciolati 7I, I-35 127 Padova, Italy \\ Received 1 June 1991/Accepted 8 July 1991
}

\begin{abstract}
It has been recently reported that phenylmethanesulfonyl fluoride (PMSF) when given to hens after a neuropathic organophosphate (OP) promotes organophosphate-induced delayed polyneuropathy (OPIDP). Chicks are resistant to OPIDP despite high inhibition/aging of neuropathy target esterase (NTE), the putative target of OPIDP initiation. However, when PMSF $(300 \mathrm{mg} / \mathrm{kg}$ s.c.) is given to chicks after di-butyl 2,2-dichlorovinyl phosphate (DBDCVP, 1 or $5 \mathrm{mg} / \mathrm{kg}$ s.c.), OPIDP is promoted. Inhibition/aging of at least $30 \%$ of NTE was thought to be an essential prerequisite for promotion to be elicited in adult hens. However, we observed in hens that when NTE is maximally affected $(>90 \%)$ by phenyl $\mathrm{N}$ methyl N-benzyl carbamate ( $40 \mathrm{mg} / \mathrm{kg}$ i. v.), a non-ageable inhibitor of NTE, and then PMSF is given $(120 \mathrm{mg} / \mathrm{kg} /$ day s.c. $\times 3$ days) clinical signs of neuropathy become evident. Methamidophos $(50 \mathrm{mg} / \mathrm{kg} \mathrm{p}$. o. to hens), which produces in vivo a reactivatable form of inhibited NTE, was shown either to protect from or promote OPIDP caused by DBDCVP $(0.45 \mathrm{mg} / \mathrm{kg} \mathrm{s.c.}$ ), depending on the sequence of dosing. Because very high doses of methamidophos cause OPIDP, we considered this effect to be a "self-promoted" OPIDP. We concluded that NTE inhibitors might have different intrinsic activities for producing OPIDP once NTE is affected. Aging might differentiate highly neuropathic OPs, like DBDCVP, from less neuropathic OPs, like methamidophos, or from the least neuropathic carbamates, which require promotion in order for neuropathy to be expressed. Retrograde axonal transport in motor fibers was measured as the accumulation of 125 I-tetanus toxin in spinal cord after injection in the gastrocnemius muscle of
\end{abstract}

\footnotetext{
* Part of this work was presented at the 30th Annual Meeting of the Society of Toxicology held in Dallas, TX, USA, February-March 1991

** Visiting Scientist from the Institute for Medical Research and Occupational Health, University of Zagreb, Zagreb, Yugoslavia

*** Visiting Professor from the Toxicology Program, School of Public Health, The University of Michigan, Ann Arbor, MI, USA

Offprint requests to: M. Lotti. Universita' degli Studi di Padova, Istituto di Medicina del Lavoro, via Facciolati 71, I-35 127 Padova, Italy
}

chicks treated either with DBDCVP ( $5 \mathrm{mg} / \mathrm{kg}$ s.c.) or with DBDCVP followed by PMSF ( $300 \mathrm{mg} / \mathrm{kg}$ s.c.). Retrograde axonal transport was reduced in both groups (to about $50 \%, 10$ days after dosing) and returned to normal 27 days after dosing. However, DBDCVP-treated chicks had a mild neuropathy which recovered relatively quickly, whereas chicks to which PMSF was also given had more severe signs which did not recover by day 27 . We concluded that promotion affects a site other than NTE and that it acts at a point downstream from initiation. PMSF was also shown to promote 2,5-hexanedione (2,5-HD) neuropathy. 2,5-HD was given to hens at doses $(200 \mathrm{mg} / \mathrm{kg} /$ day i.p. $\times 8$ days $)$ which caused mild and reversible neuropathy. When PMSF $(120 \mathrm{mg} / \mathrm{kg} / \mathrm{day} \times 2$ days at the end of $2,5-\mathrm{HD}$ treatment $)$ was given, more severe and irreversible signs of neuropathy were observed. We conclude that promotion might be a common feature in neuropathies of different origin.

Key words: Organophosphate neuropathy - Neuropathy target esterase - Promotion - Phenylmethanesulfonyl fluoride - 2,5-Hexanedione - Carbamates - Methamidophos - Age sensitivity - Retrograde axonal transport

\section{Introduction}

Phenylmethanesulfonyl fluoride (PMSF) is an inhibitor of proteases and esterases (Prouty and Goldberg 1972) with low cholinergic toxicity. PMSF has been used in mechanistic studies of organophosphate-induced delayed polyneuropathy (OPIDP) because it protects hens from this toxicity (Johnson 1982). When neuropathy target esterase (NTE), the putative target for the initiation of OPIDP, is sulfonylated in vivo by PMSF prior to neuropathic doses of organophosphates (OPs), no OPIDP develops (Johnson 1974; Lotti et al. 1987). PMSF shares this effect with other NTE inhibitors, e.g., some phosphinates and carbamates. It 
is thought that OPIDP develops when enough NTE ( $>70 \%$ ) is modified by a two-step mechanism, involving inhibition of the enzyme and a subsequent intramolecular rearrangement called "aging" (Johnson 1982). Protection occurs because sulfonylated, phosphinylated and carbamylated NTEs are not able to undergo the "aging" reaction (Johnson 1982). Consequently, by occupying NTE in a non-ageable form they prevent the phosphorylation/aging of NTE by neuropathic OPs.

However, it has been shown recently that when PMSF or other non-ageable inhibitors are given after a neuropathic OP they promote OPIDP (Pope and Padilla 1990; Lotti et al. 1991). Thus far promotion was caused only by nonageable NTE inhibitors at doses which were inhibitory to NTE (when given to naive birds), and when about $30 \%$ of NTE was affected by the initiating OP (Lotti et al. 1991).

We report in this paper further studies aimed at understanding the significance of promotion. In particular, we addressed some known exceptions in OPIDP to determine whether they remain as such when promotion is given. Thus, we observed that PMSF promotes OPIDP in chicks, which are known to be resistant to this toxicity (Johnson and Barnes 1970). Age-related resistance occurs despite the high inhibition/aging of NTE in the nervous tissues of young animals (Moretto et al. 1991), even though it can be partially overcome by increasing the single dose of the neuropathic OP (Peraica et al. 1991).

A notable exception as far as aging is concerned has been recently reported. Methamidophos (O,S-dimethyl phosphorothioamidate) causes OPIDP in the hen at exceedingly high doses but inhibited brain NTE can be fully reactivated by KF, suggesting that aging had not occurred (Johnson et al. 1991). We report in this paper another exception of this type. High doses of phenyl N-methyl $\mathrm{N}$-benzyl carbamate (PMBC), which caused high levels of non-ageable carbamylated NTE, produced neuropathy in hens only when a subsequent promoting dose of PMSF was given. Just as PMBC can both protect and promote neuropathy (Lotti et al. 1991) methamidophos was also found to cause both protection and promotion in hens, depending on the sequence of dosing with a neuropathic OP.

The results of these experiments on exceptions in OPIDP indicate that the mechanism of promotion might be different from that of initiation. This contention was supported by the following findings.

First, retrograde axonal transport, which is selectively reduced in OPIDP (Moretto et al. 1987), was not affected by promotion when assessed in young chicks.

Second, the peripheral neuropathy caused by 2,5hexanedione $(2,5-\mathrm{HD})$, which has a different mechanism of initiation from that of OPIDP (DeCaprio 1987), but also proceeds with a reduction of retrograde axonal transport (Braendgaard and Sidenius 1986), was also promoted by PMSF in hens.

\section{Materials and methods}

Chemicals. Acetonylacetone (2,5-hexanedione; 2,5-HD), 97\% purity and atropine sulfate were purchased from Aldrich-Chemie, Steinheim, FRG. O,S-dimethyl phosphorothioamidate (methamidophos) was purchased from Societa' Italiana Chimici, Rome, Italy. Phenylmethanesulfon fluoride (PMSF) and diisopropylphosphorofluoridate (DFP) were pu chased from Fluka AG Chem. Fabrik, Buchs, Switzerland. Phenyl methyl N-benzyl carbamate (PMBC) was purchased from the Medic Research Council, Carshalton, UK. Di-butyl 2,2-dichlorovinyl phosphal (DBDCVP) was purchased from Ash Stevens, Detroit, MI, USA. Dieth p-nitrophenyl phosphate (paraoxon) was purchased from Sigma Chemi cal Co., St Louis, MO, USA. Phenyl valerate and $\mathrm{N}, \mathrm{N}^{\prime}$-diisoprop: phosphorodiamidofluoridate were purchased from Lark Enterprise Webster, MA, USA. Tetanus toxin was kindly supplied by Dr. Monk cucco, Dept of General Pathology, University of Padua and N-succin midyl 3-(4 hydroxy-5-[ ${ }^{125}$ I $]$-iodophenyl) propionate was purchash from Amersham, UK.

Animals. Randomly bred adult hens (1.7-2.7 kg body wt) and Warte strain female chicks (36-40 days of age) were purchased from a lo: breeder, caged in groups of five to ten, and allowed food and water libitum.

All chemicals given to animals were dissolved immediately befo. administration in glycerol formal (Fluka) except methamidophos an 2,5-HD, which were dissolved in water. Pretreatment with atropine sil fate $(20 \mathrm{mg} / \mathrm{kg}$ i. p.) to counteract cholinergic toxicity was given in i experiments, except in those with 2,5-HD, DBDCVP $(1 \mathrm{mg} / \mathrm{kg})$ ak PMSF. Maximal volumes used were the following: $0.5 \mathrm{ml} / \mathrm{kg}$ p.e $1.5 \mathrm{ml} / \mathrm{kg} \mathrm{s.c.,} 1.0 \mathrm{ml} / \mathrm{kg}$ i.p., and $0.13 \mathrm{ml} / \mathrm{kg} \mathrm{i.} \mathrm{v.}$

Clinical signs of ataxia were evaluated on a $0-8$ point scale accort ing to Lotti et al. (1991).

Animals were killed by decapitation and brain, lumbosacral spin. cord and sciatic nerve were excised immediately and either placed ice-cold $50 \mathrm{mM}$ TRIS- $\mathrm{HCl}$ buffer $\left(\mathrm{pH} 8.0\right.$ at $23^{\circ} \mathrm{C}$ ) containing $0.2 \mathrm{m!}$ EDTA and assayed for NTE or stored at $-80^{\circ} \mathrm{C}$ prior to assay.

NTE assays. NTE was measured in the brain according to Johnson (197 and in the peripheral nerve according to Caroldi and Lotti (1982): modified by Moretto et al. (1989). NTE activities of control hens wer always within the range of historical values from our laboratory: $2.0-2$. in brain, $0.5-0.7$ in the spinal cord and $0.1-0.15$ in the peripheral nen $(\mu \mathrm{mol} / \mathrm{min} / \mathrm{g}$ wet wt of tissue).

Retrograde axonal transport. Retrograde axonal transport was measur: in motor fibers of sciatic nerve of chicks as the accumulation of ${ }^{125} \mathrm{It}$ the spinal cord $28 \mathrm{~h}$ after injection of labelled tetanus toxin into th gastrocnemius muscle according to Moretto et al. (1987). ${ }^{125}$ I telau. toxin was prepared according to Rogers and Snyder (1981). The specifi ity of iodination was checked by autoradiography of a gel electropho: togram of the eluate containing high radioactivity.

Animals were injected with ${ }^{125}$ I-tetanus toxin 5, 10, and $27 \mathrm{~d}$ : after the treatments.

\section{Results}

The promoting effect of PMSF in chicks is shown it Table 1. DBDCVP ( $1 \mathrm{mg} / \mathrm{kg} \mathrm{s.c})$ and DFP ( $1.5 \mathrm{mg} / \mathrm{kg} \mathrm{s.c}$ failed to cause OPIDP when given alone, but promotion occurred when PMSF was given afterwards. However. mild OPIDP was observed with a higher dose of DBDCV? ( $5 \mathrm{mg} / \mathrm{kg} \mathrm{s.c.)}$, which was also promoted by subsequentl administered PMSF. The promoting effect of PMSF wa stronger in DFP-treated chicks (clinical score increaset from 0 to 5.1) than that in DBDCVP-treated chicks (clin: cal score increased from 1.8 to 5.1 ).

Table 2 shows that when PMBC was used instead of $x$. OP to "initiate OPIDP", then clinical neuropathy occurre" after PMSF treatment. However, when the sequence of dosing of the same compounds was reversed, a margina response was observed in two animals only. 
Table 1. OPIDP promotion by PMSF in chicks ${ }^{\mathrm{a}}$

\begin{tabular}{lll}
\hline $\begin{array}{l}\text { Initial dosing } \\
(\mathrm{mg} / \mathrm{kg} \mathrm{s.} \mathrm{c.)}\end{array}$ & $\begin{array}{l}\text { PMSFb } \\
(300 \mathrm{mg} / \mathrm{kg} \mathrm{s.c.})\end{array}$ & $\begin{array}{l}\text { Clinical scorec } \\
(\text { mean } \pm \mathrm{SD})\end{array}$ \\
\hline DBDCVP (1)d & Solvent & $0(5)$ \\
DBDCVP (1) & + & $2.0 \pm 1.4(4)$ \\
DBDCVP (5) & Solvent & $1.8 \pm 1.3(12)$ \\
DBDCVP (5) & + & $5.1 \pm 1.5(10)$ \\
DFP (1.5) & Solvent & $0(8)$ \\
DFP $(1.5)$ & + & $5.1 \pm 1.3(8)$ \\
\hline
\end{tabular}

a 39 days of age at the beginning of the experiment

b Given $24 \mathrm{~h}$ later. This dose does not cause OPIDP and inhibits more than $90 \%$ of brain NTE (Lotti et al. 1991)

c Maximal scores are reported and were reached 12-15 days from the beginning of the experiments. Number of animals in brackets

d This dose given to 20-day-old chicks causes about $80 \%$ NTE inhibition in peripheral nerve (Moretto et al. 1991)

c This dose given to 36-day-old chicks causes $70 \pm 11 \%$ NTE inhibition in peripheral nerve $(n=3$; mean $\pm \mathrm{SD}$; activity of control was $1.71 \pm 0.06 \mathrm{nmol} / \mathrm{min} / \mathrm{mg}$ of protein)
Table 2. Promotion of neuropathy in hens treated with a combination of PMSF and PMBC

\begin{tabular}{lll}
\hline Dosing & Clinical score \\
\hline PMBC $(40 \mathrm{mg} / \mathrm{kg} \text { i.v. } \times 3)^{\mathrm{a}}$ & $0(n=9)$ \\
PMSF $(120 \mathrm{mg} / \mathrm{kg} \mathrm{s.c.} \times 3)^{\mathrm{b}}$ & $0(n=2)$ \\
PMBC $(40 \mathrm{mg} / \mathrm{kg} \text { i.v. })^{\mathrm{c}}$ & $\begin{array}{l}(120 \mathrm{mg} / \mathrm{kg} \text { s.c. } \times 3)^{\mathrm{d}} \\
\text { PMSF }(120 \mathrm{mg} / \mathrm{kg} \text { s.c. } \times 3)\end{array}$ & $\begin{array}{l}2,2,2,2 \\
(40 \mathrm{mg} / \mathrm{kg} \text { i. v. })^{\mathrm{c}}\end{array}$ \\
\hline
\end{tabular}

a Treatments were given $5 \mathrm{~h}$ apart. In one animal killed $7 \mathrm{~h}$ after the last dose, brain NTE activity was $93 \%$ inhibited

b Treatment was given $12 \mathrm{~h}$ apart. In one animal killed $24 \mathrm{~h}$ after the last dose, brain and peripheral nerve NTE activities were $98 \%$ and $88 \%$ inhibited, respectively. PMSF (120 mg/kg s.c.) caused about $93 \%$ inhibition of brain NTE when measured $24 \mathrm{~h}$ after treatment (Lotti et al. 1991). No ataxia was observed when either a single dose of $480 \mathrm{mg} / \mathrm{kg} \mathrm{s}$. c. or 9 daily doses of $30 \mathrm{mg} / \mathrm{kg} \mathrm{s}$. c. of PMSF were given

c PMBC $(40 \mathrm{mg} / \mathrm{kg}$ i. v.) causes $80-90 \%$ inhibition of brain NTE (Lotti et al. 1991) when measured $5 \mathrm{~h}$ after treatment

d Given 5, 17, and $29 \mathrm{~h}$ after PMBC

e Given $24 \mathrm{~h}$ after the last dose of PMSF

Table 3. Promotion of and protection from DBDCVP neuropathy by methamidophos in hens

\begin{tabular}{|c|c|c|c|c|}
\hline \multirow[t]{2}{*}{ Dosing $(\mathrm{mg} / \mathrm{kg})^{\mathrm{a}}$} & \multirow{2}{*}{$\begin{array}{l}\text { Clinical score } \\
\text { mean } \pm S D(n)\end{array}$} & \multicolumn{3}{|c|}{ \% NTE activityb } \\
\hline & & Brain & Spinal cord & Peripheral nerve \\
\hline $\operatorname{DBDCVP}(0.45$ s.c. $)$ & $3.1 \pm 1.4(9)$ & $10 \pm 1^{\mathrm{c}}$ & $17 \pm 3^{c}$ & $46 \pm 9 c$ \\
\hline DBDCVP $(0.45$ s. c. $)+$ methamidophos (50 p.o.) & $6.2 \pm 0.4(5)$ & 8 & 12 & 12 \\
\hline Methamidophos (50 p.o.) & $0(3)$ & 50 & 52 & 45 \\
\hline Methamidophos ( 50 p. o.)+DBDCVP (0.45 s.c.) & $0(4)$ & 12 & 12 & 24 \\
\hline Methamidophos ( 25 p.o.) & - & 76 & 73 & 73 \\
\hline Methamidophos ( 25 p.o.)+DBDCVP ( 0.45 s.c.) & $4.3 \pm 0.6(3)$ & - & - & - \\
\hline Methamidophos (5 p.o.) & - & 83 & 67 & 100 \\
\hline Methamidophos ( 5 p.o. $)+$ DBDCVP $(0.45$ s. c.) & $4.6 \pm 1.1(3)$ & - & - & - \\
\hline
\end{tabular}

a Treatments were given $24 \mathrm{~h}$ apart

b Measured $24 \mathrm{~h}$ after last dosing. Expressed as percentage of NTE activity of a concurrent control. Control activity was within historical values from our laboratory (see Materials and methods)

c Data from Moretto et al. (1989)

Table 3 shows that methamidophos $(50 \mathrm{mg} / \mathrm{kg}$ p.o.) both protected from and promoted DBDCVP neuropathy, depending on the sequence of dosing. However, lower doses of methamidophos given prior to DBDCVP failed to protect birds, because most of the NTE activity was left for phosphorylation by DBDCVP. The severity of OPIDP in such birds was not different from that seen in birds treated with DBDCVP only.

Figure 1 shows the clinical effects of DBDCVP and of DBDCVP followed by PMSF in chicks, together with the reduction of retrograde axonal transport. DBDCVP caused a mild and reversible OPIDP, whereas when PMSF was also given, birds were more severely affected and recovery was much delayed. In contrast with these time-courses of clinical effects, the accumulation of 125 I-tetanus toxin showed a progressive reduction and then a full recovery in both groups.

Figure 2 shows the promoting effect of PMSF when given after repeated doses of 2,5-HD which caused on its own a mild neuropathy in some hens only. PMSF exacerbated the severity of signs, caused all animals to be affected, and delayed the recovery.

\section{Discussion}

OPIDP promotion by PMSF was shown in the hen after OP doses which do not cause overt clinical signs (Pope and Padilla 1990; Lotti et al. 1991). This effect was confirmed in chicks but it is different in as much as promotion overcomes their resistance to OPIDP whereas in hens causes a "subthreshold" inhibition/aging of NTE to be expressed clinically (Lotti et al. 1991). Because maximal inhibition/aging of NTE in chicks is not enough to trigger clinical OPIDP (Moretto et al. 1991), they might differ from the hen either because of lack of progression of the lesion or of a more efficient repair. Consequently, promotion by PMSF in chicks should affect one or both of these functions, which seem unrelated to NTE.

Promotion caused clinical responses of similar size independently from the initial effect of different compounds. In fact, the clinical score was higher in chicks treated with DBDCVP $(5 \mathrm{mg} / \mathrm{kg})$ than that in birds treated with DFP, whereas after PMSF it was the same in both groups. A similar phenomenon was observed when promotion was given to chicks of different age (Peraica et al. 1991; Pope 


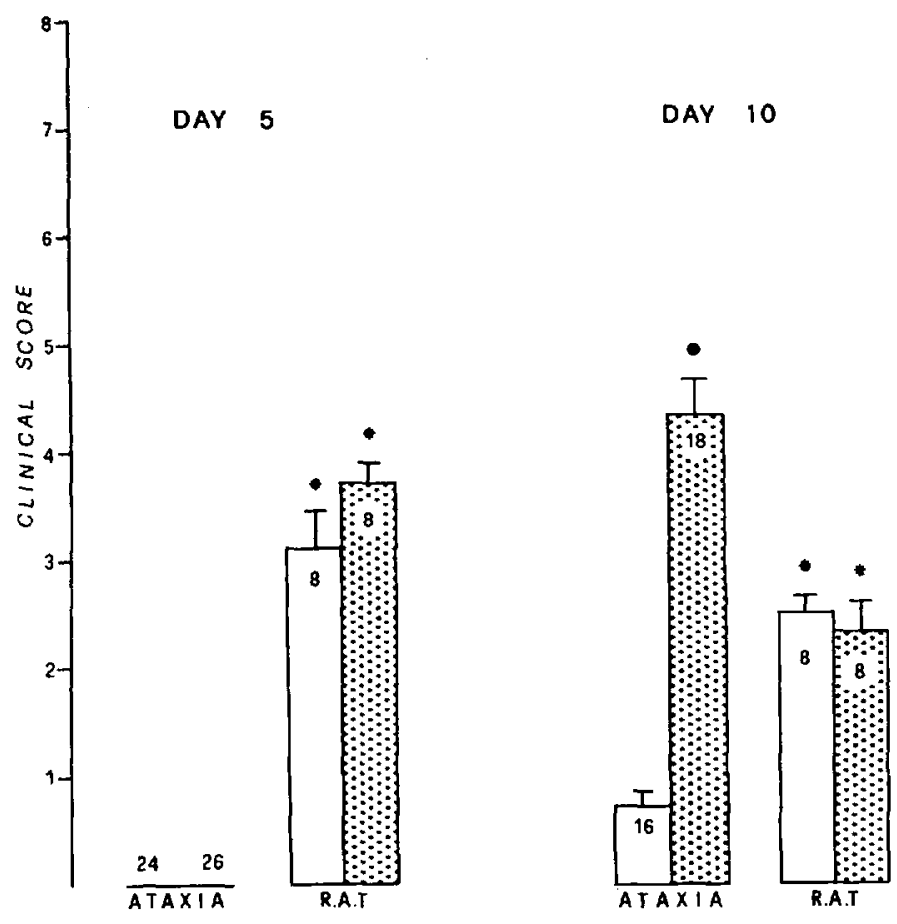

Fig. 1. Effects on clinical behavior and retrograde axonal transport (R. A. T.) in motor fibers of sciatic nerve, in chicks treated with DBDCVP alone ( $\square$ ) and in combination with PMSF (圈). Fifty chicks of 40 days of age were injected with DBDCVP $(5 \mathrm{mg} / \mathrm{kg} \mathrm{s}$. c.) after pretreatment with atropine and $24 \mathrm{~h}$ later either with solvent or with PMSF (300 mg/kg s.c.). ${ }^{125}$ I-tetanus toxin was injected on days 5,10 and 27. Data are expressed as mean percentage ( $\pm \mathrm{SE}$ ) of the mean of controls. The same preparation of ${ }^{125}$ I-tetanus toxin was used on days 5 and 10 but

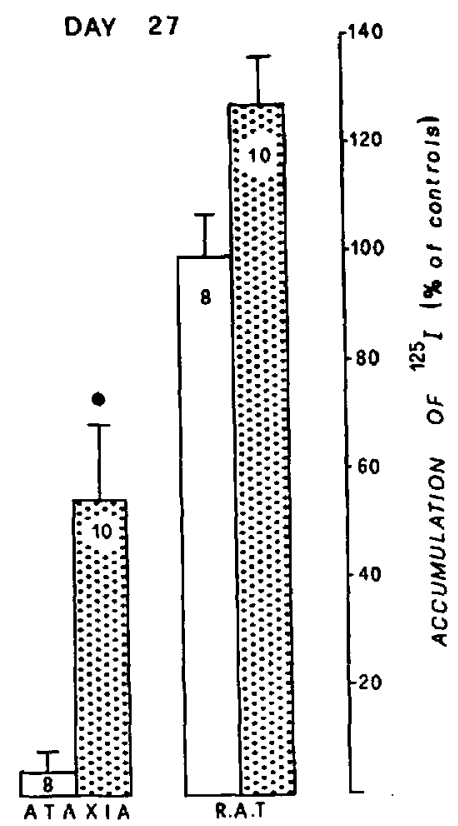

differently diluted. Control values for 125 I-accumulation were, day $5=5698 \pm 738 \mathrm{CPM}$ (mean \pm SD, 8 animals), on day 10 $3834 \pm 1277$ CPM ( 8 animals) and on day $27=1712 \pm 496$ CPM (7a mals). * Significantly different from controls and day 27 , by one-x: analysis of variance (Kruskal-Wallis test, $p<0.05$ ). - Significan different from animals treated with DBDCVP only, Wilcoxon is $(p<0.001)$
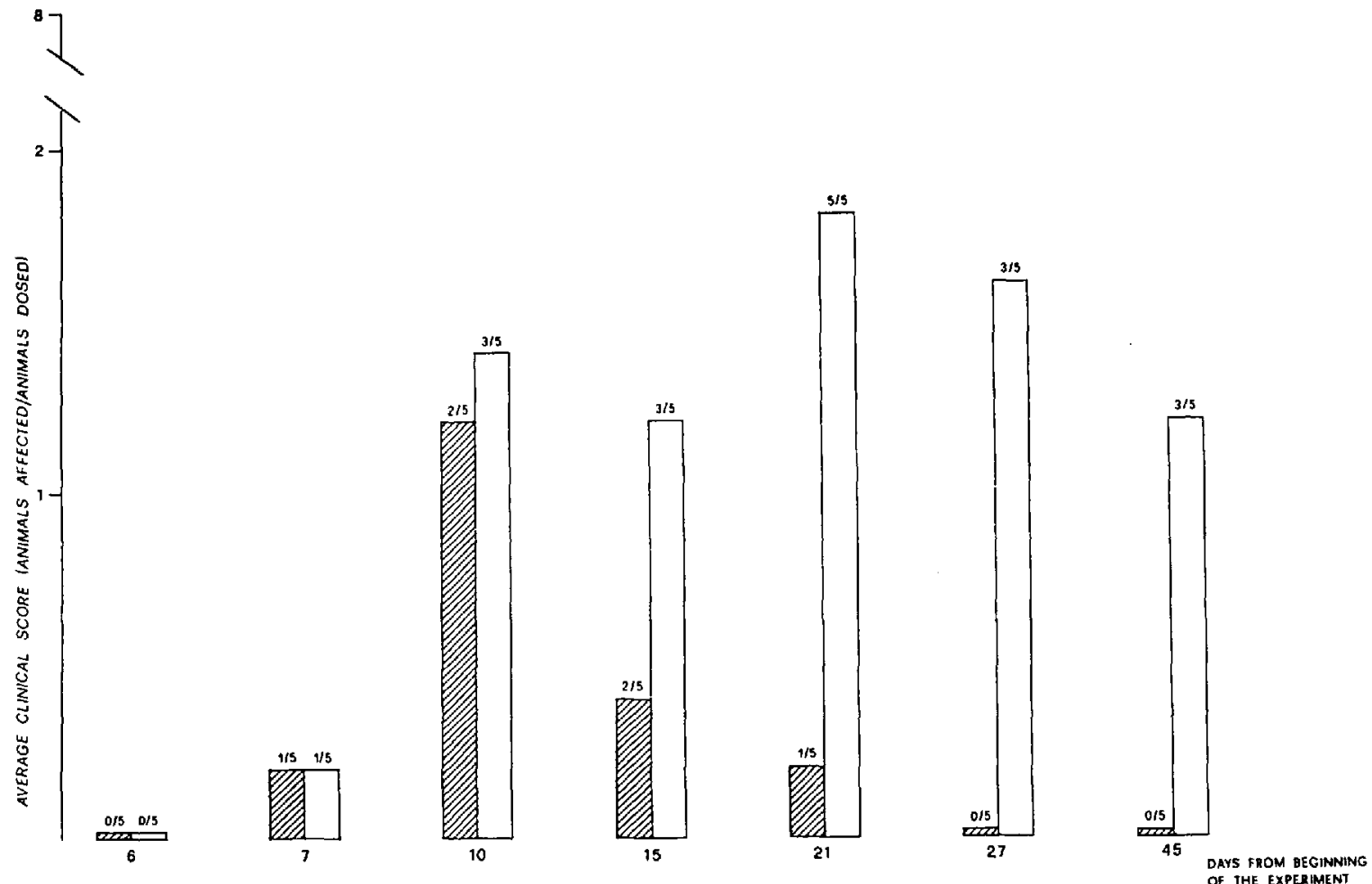

Fig. 2. Development of $2,5-\mathrm{HD}$ neuropathy $(\mathbb{\$})$ in hens $(200 \mathrm{mg} / \mathrm{kg}$ i. p. $\times 8$ daily) and the influence of two subsequent doses of PMSF $(120 \mathrm{mg} / \mathrm{kg} . \mathrm{s}$ daily) ( $\square$ ). Two birds dosed with PMSF prior to 2,5-HD had mild neuropathy with a time course similar to that in birds treated with 2,5-HD only 
and Padilla 1991). Indeed, regardless of age susceptibility to OPs, PMSF promoted OPIDP to a similar degree of severity. These observations imply either a maximal promoting effect, or that phosphorylated NTE at different ages or with different OPs varies in its capability to initiate OPIDP, or both. Besides their inhibitory power, NTE inhibitors might therefore display different intrinsic activities with respect to initiation of OPIDP, once attached to NTE. Thus, PMSF promotion may represent a combination of different degrees of OPIDP initiation plus the same maximal promoting effect.

The hypothesis that NTE inhibitors might have different intrinsic activities (Lotti et al. 1991) is supported by results on PMBC and methamidophos. N-Methyl N-benzyl carbamylated NTE does not age (Johnson 1982) and consequently no neuropathy develops when this compound is given on its own. However, PMBC becomes neuropathic when PMSF treatment follows. Methamidophos causes OPIDP at very high doses when almost all NTE is affected in a non-ageable form (Johnson et al. 1991). When given at lower doses it protects from and promotes DBDCVP neuropathy, depending on the order of dosing. Looking at NTE as a receptor, inhibitors will behave like partial agonists (such as PMBC and methamidophos, causing protection or weak initiation) or like full agonists (such as DBDCVP, causing neuropathy), where the capability to age would confer the property of a full agonist. Therefore, PMBC neuropathy is expressed only by PMSF promotion, whereas methamidophos neuropathy is "self-promoted" when exceedingly high doses are given. OPIDP in resistant chicks caused by very high doses of OPs (Peraica et al. 1991) may also be interpreted as "self-promotion".

Promotion has no effect on retrograde axonal transport, because the clinical scores of DBDCVP-treated chicks are less severe than those of chicks treated also with PMSF, whereas the reductions of retrograde axonal transport are similar in the two groups. Because reduction of retrograde axonal transport is involved in the pathogenesis of OPIDP (Moretto et al. 1987) measurement of retrograde axonal transport might discriminate between progression of the lesion and other mechanisms affecting the clinical outcome.

Given the results of NTE inhibition in the hen after much smaller doses of DBDCVP (Moretto et al. 1987) we might assume that almost all NTE was inhibited in chicks by DBDCVP before PMSF was given. Taking into account also methamidophos (Johnson et al. 1991) and PMBC data where promotion occurred after maximal NTE inhibition, we conclude that NTE is probably not the target of promotion.

The mechanism of 2,5-HD neuropathy is thought to involve the formation of adducts to $\varepsilon$-amino groups of lysine residues in subunit proteins of neurofilaments and subsequent crosslinking (DeCaprio 1987). Because this target is different from that of OPIDP and yet PMSF promotes both neuropathies, promotion must act at a point in common downstream from initiation. It is possible that neuropathies produced by different means will also be promoted by PMSF.

In conclusion, these experiments suggest that the aging of inhibited NTE is not necessary to initiate neuropathy.
However, the initiation of neuropathy correlates with NTE inhibition. Inhibitors might have a very low intrinsic activity (PMSF < PBMC < methamidophos) or high intrinsic activity (DFP $<$ DBDCVP), once they are attached to NTE. The aging reaction might differentiate full agonists from others. Promotion seems to be separate from progression of the initial lesion and to reach a maximum effect. Perhaps promotion involves a mechanism of either degeneration in the cascade of events which follow initiation and/or repair common to all degenerating axons. It also appears that promotion affects a site other than NTE, although it has to be explained why, so far, only NTE inhibitors act as promoters (Lotti et al. 1991).

Acknowledgeme'ns. We wish to thank Ms. F. Patsqualato for technical assitance and Ms. C. A. Drace-Valentini and Ms. G. Tono for manuscript preparation. M. P. is a recipient of a Fellowship in Toxicology from the European Science Foundation and R. J. R. wals supported in part by Fidia (Abano, Italy). The financial support of CNR, Ministero Italiano della Ricerca Scientifica and Regione Veneto is gratefully acknowledged. The research reported herein has also been supported by Bayer AG, D-5090 Leverkusen, FRG. The conclusions are those of the aluthors and not of the sponsors.

\section{References}

Braendgaard H, Sidenius $P$ (1986) The retrograde fast component of axonal transport in motor and sensory nerves of the rat during administration of 2,5-hexanedione. Brain Res 378: $1-7$

Caroldi S, Lotti M (1982) Neurotoxic esterase in peripheral nerve: assay, inhibition and rate of resynthesis. Toxicol Appl Pharmacol 62: $498-501$

De Caprio AP (1987) Hexane neuropathy: studies in experimental animals and man. In: DeMatteis F, Lock EA (eds) Selectivity and molecular mechanisms of toxicity. MacMillan Press, London, pp 249-263

Johnson MK (1974) The primary biochemical lesion leading to the delayed neurotoxic effects of some organophosphorus esters. J Neurochen 23: 785-789

Johnson MK (1977) Improved assay of neurotoxic esterase for screening organophosphates for delayed neurotoxicity potential. Arch Toxicol 37: $113-115$

Johnson MK (1982) The target for initiation of deliyed neurotoxicity by organophosphorus esters! biochemical studies and toxicological applications. Rev Biochem Toxicol 4: 141-212

Johnson MK, Barnes JM (1970) Age and the sensitivity of chicks to the delayed neurotoxic effects of some organophosphorus compounds. Biochem Pharmacol 19: 3045-3047

Johnson MK. Vilanova E, Read DJ (1991) Anonulous biochemical responses in tests of delayed neuropathic polential of methamidophos (O,S-dimethyl phosphorothioamidate), its resolved isomers and of some higher O-alkyl homologues. Arch Toxicol (in press)

Lotti M. Caroldi S. Moretto A, Johnson MK, Fish C, Gopinath G, Roberts NL (1987) Central-peripheral delayed neuropathy caused by diisopropyl phosphorofluoridate (DFP): segregation of peripheral nerve and spinal cord effects using biochemical, clinical and morphological criteria. Toxicol Appl Pharmacol 88: 87-96

Lotti M, Caroldi S, Capodicasa E, Moretto A (1991) Promotion of organophosphate induced delayed neuropathy by phenylmethanesulphonyl fluoride. Toxicol Appl Pharmacol 108: 234-241

Moretto A, Lotti M, Sabri M, Spencer PS (1987) Progressive deficit of retrograde axonal transpon is involved in the pathogenesis of di-nbutyl dichlorvos axonopathy. J Neurochem 49: $1515-1522$

Moretto A, Lotti M, Spencer PS (1989) In vivo and in vitro regional differential sensitivity of neuropathy target esterase to di-n-butyl 2,2-dichlorovinyl phosphate. Arch Toxicol 63: 469-473 
Moretto A, Capodicasa E, Peraica M, Lotti M (1991) Age sensitivity to organophosphate induced delayed polyneuropathy. Biochemical and toxicological studies in developing chicks. Biochem Pharmacol 41: $1497-1504$

Peraica M, Capodicasa E, Scapellato ML, Bertolazzi M, Moretto A, Lotti M (1991) Organophosphate-induced delayed polyneuropathy (OPIDP) in chicks: induction, promotion and recovery. Toxicologist 11: 306

Pope CN, Padilla S (1990) Potentiation of organophosphorus-induced delayed neurotoxicity by phenylmethylsulfonyl fluoride. J Toxicol Environ Health 31: $261-273$
Pope CN, Chapman M, Arthun D, Tanaka D, Padilla S (1991) Ag sensitivity to organophosphorus-induced delayed neurotoxicit (OPIDN): effects of phenlymethylsulphonylfluoride (PMSF). Tos: cologist 11:304

Prouty WF, Goldberg AL (1972) Effects of protease inhibitors on protei: breakdown in Escherichia coli. J Biol Chem 247: 3341 - 3352

Rogers TB, Snyder SH (1981) High affinity binding of tetanus toxin: mammalian brain membranes. J Biol Chem 256: 2402 - 2407 